\title{
DEVELOPMENT OF BEST PRACTICE GUIDELINES FOR CFD IN NUCLEAR REACTOR SAFETY
}

\author{
JOHN MAHAFFY \\ WheelSmith Farm \\ 532 Lower Georges Valley Rd., Spring Mills, PA 16875 \\ "Corresponding author. E-mail : mahaffy@psu.edu
}

Received July 14, 2010

In 2007 the Nuclear Energy Agency's Committee on the Safety of Nuclear Installations published Best Practice Guidelines for the use of CFD in Nuclear Reactor Safety. This paper provides an overview of the document's contents and highlights a few of its recommendations. The document covers the full extent of a CFD analysis from initial problem definition and selection of an appropriate tool for the analysis, through final documentation of results. It provides advice on selection of appropriate simulation software, mesh construction, and selection of physical models. In addition it contains extensive discussion of the verification and validation process that should accompany any high-quality CFD analysis.

KEYWORDS : CFD, Best Practice, Nuclear Reactor Safety

\section{INTRODUCTION}

This paper describes Best Practice Guidelines (BPG) for the use of Computational Fluid Dynamics (CFD) in Nuclear Reactor Safety (NRS) [1], published in May of 2007 by the Nuclear Energy Agency, Committee on the Safety of Nuclear Installations (CSNI). Creation of the report started in 2003 with the formation of a writing group, tasked to explore the need for guidelines on the use of CFD in single phase NRS applications. This writing group submitted a final report to the CSNI Working Group on Analysis and Management of Accidents (GAMA) in September 2004, summarizing existing BPG documents for CFD, and recommending creation of a new BPG document specifically for Nuclear Reactor Safety (NRS) applications. Twelve member organizations of GAMA chose to participate in writing the document. These organizations are listed in the acknowledgements at the end of this paper as are their representatives who acted as co-authors of the report.

The BPG document's primary purpose is to provide practical guidance for application of single phase CFD to the analysis of Nuclear Reactor Safety (NRS). We consider use of CFD programs solving Reynolds Average NavierStokes (RANS) equations on both regular and unstructured meshes, as well as use of Large Eddy Simulation (LES), and Detached Eddy Simulation (DES). Very little is said about Direct Numerical Simulation (DNS), as it is only practical for a very limited range of NRS applications. We have attempted to cover the full range of issues associated with a high quality analysis. This begins with proper definition of the problem to be solved, permitting selection of an appropriate simulation tool. For the probable range of tools, we provide generic guidance on selection of physical models and on numerical issues including creation of an appropriate spatial grid. To complete the process of analysis, we also provide guidance for verification of the input model, validation of results, and documentation of the project.

Although our primary target audience could be considered to be less experienced CFD users, the document should be valuable to a wider audience. High quality CFD analysis is a complex process with many steps, and many opportunities to forget important details. More experienced CFD users should find value in the checklist of steps and considerations provided at the end of the document. Project managers should find the discussion useful in establishing level of effort for a new analysis. Regulators should find the document to be a valuable source of questions to ask those using CFD to support licensing requests.

There are already a number of other useful documents providing guidelines for the use of CFD. The most notable in the area of reactor safety analysis was produced by the ECORA project [2]. The European Research Community On Flow, Turbulence And Combustion (ERCOFTAC) produced a more general set of guidelines for creation of CFD input models [3], [4]. Similar guidelines were produced specifically for marine applications by MARNET [5]. The AIAA has produced a short guidelines document on verification and validation [6]. More details on verification 
and validation can be found in a book by Patrick Roach [7], and in publications by William Oberkampf and his colleagues at Sandia National Laboratories $[8,9]$.

The BPG document was intended to be as internally complete as possible. Specific guidance, that might also be available in the above publications, is provided here in the context of NRS and our experience with CFD. However, "internally complete" does not imply that the document is exhaustive. We make no attempt to cover the full history of turbulence theory and modeling, nor the full range of turbulence models available today in CFD applications. For more details on these subjects, we recommend reading a text on CFD such as the recent work by David Wilcox [10].

The remainder of this paper contains a general summary of the BPG document's contents, and some discussion of key findings in the report.

\section{SUMMARY OF BPG CONTENTS}

The BPG document begins with a summary of NRS related CFD analysis in countries represented by the authors, to give a feeling for the existing range of experience. Examples cited in the summary date back as far as the late 1970 's, but most analyses discussed were performed after 2000. Chapter 2 defines some key terminology in the field. These definitions are not meant simply for novices, but also provide experienced users with an understanding of how some terms (e.g. verification and validation) are used within the document.

Chapter 3 emphasizes the need for a careful initial definition of the problem and its solution approach. This includes isolation of the portion of the NRS problem most in need of CFD, and use of a classic thermalhydraulic (TH) safety code to provide boundary conditions for the CFD. The chapter discusses the Phenomena Identification and Ranking Table (PIRT) process [11], which identifies phenomena critical to the problem, provides a basis for selection of an appropriate simulation tool, and establishes the foundation for the validation process needed for confidence in final results. The chapter also discusses theory and modeling needs associated with a number of special phenomena important to NRS but not commonly modeled in the CFD community.

CFD is not always the optimal approach to problem solution. In many cases the level of detail required for results can be obtained in much less time with thermalhydraulic systems codes or special purpose reactor component codes. Chapter 4 provides guidance in choosing between these options, and also discusses use of a transient calculation with tightly coupled CFD and TH codes.

Chapter 5 discusses selection of physical models available as user options. As is appropriate for single phase CFD, most of the emphasis is on selection of turbulence models. Recommendations are provided for high-level selection between Reynolds Averaged Navier Stokes (RANS), Large Eddy Simulation (LES), and hybrid approaches such as Detached Eddy Simulation (DES). Specific turbulence models available with each of these approaches are also described. Recommendations are also provided for models associated with buoyancy, heat transfer, free surfaces, and fluid structure interactions.

Chapter 6 focuses on the numerical approximations available to solve the flow equations. Guidelines are provided for nodalization, and for choice of discrete approximations to the differential equations. For those contemplating first order spatial differencing, we reinforce our recommendation against that approach with a simple formula estimating the level of numerical diffusion associated with the difference scheme [12] for comparison against turbulent diffusion. Guidance is also given on convergence of iterative solutions, and numerical techniques for following free surfaces.

Results from any simulation must be properly justified. Chapter 7 discusses general assessment strategy for a NRS calculation. Chapter 8 covers approaches to limiting errors. A significant portion of the chapter describes quantifying and controlling errors associated with discretization and numerical solution methods. This step is a necessary precursor to quantifying errors associated with physical models (validation) as described in Chapter 9. All of these steps must, of course, be properly documented both for immediate review and archival purposes. Guidance on documentation is provided in Chapter 10.

Chapter 11 provides some examples of NRS applications. These are not intended as comprehensive illustrations of best practices, but illustrate some of these practices for very specific NRS applications. The first two examples are boron dilution and pressurized thermal shock. These scenarios have been analyzed for many years by a number of organizations, and references to some of these other studies can be found in Chapter 1. The third example explores the use of CFD for simulation of dry cask storage of spent fuel, and the fourth is a study of hydrogen distribution in a containment during a severe accident.

\section{MODELING GUIDELINES}

The document provides general guidance on construction of a spatial mesh and selection of an appropriate turbulence model. In addition it contains extended discussion of special modeling needs within single phase CFD for: containment wall condensation; pipe wall erosion; thermal cycling; hydrogen explosion; fire analysis; water hammer; liquid metal systems; and natural convection.

References are provided to a wide range NRS analyses, covering a full range of plant types, including:

- turbulent flows in various rod bundles;

- pressurized thermal shock;

- boron dilution transients; 
- flow mixing and stratification in plant loops;

- natural circulation in the reactor primary;

- thermal fatigue in a mixing tee;

- hydrogen distribution in a containment during a severe accident;

- hydrogen recombiners;

- break induced by high temperature steam during a severe accident;

- detailed analyses to improve understanding of boiling heat transfer;

- natural circulation in pools;

- steam jet driven circulation in pools;

- strainer clogging in a containment sump;

- fluid/structure interactions (particularly at the start of a large break).

Extended discussion is provided for a boron dilution validation exercise using experimental results from the ROCOM mixing test facility [13]. As part of the exercise the ECORA Best Practice Guidelines were followed and some special benchmark problems were used to study the impact of turbulence model selection, discretization schemes, boundary conditions, nodalization, and time step size. Mesh sensitivity studies revealed specific regions in the test facility requiring more care in grid specification and resulted in a mesh with 7 million elements. Of the turbulence models studied SST was found to produce the best match to data on the final mesh.

An analysis of the Upper Plennum Test Facility (UPTF) [14] Test 1 was used as a sample simulation of Pressurized Thermal Shock (PTS)[15]. In this test cold (300K) ECC is injected into a cold leg containing stagnant $463 \mathrm{~K}$ water. The cold stream follows the bottom of the pipe into the downcomer in one direction and the pump in the other direction. Experimental data showed oscillations in the cold stream falling through the downcomer. Studies of k$\varepsilon$ and SST-k- $\omega$ turbulence models showed a need for buoyancy modifications to both. With these modifications results from the two models were very similar. However, a Reynolds Stress model was needed to best capture the amplitude of the flow oscillations. Large Eddy Simulation (LES) was not attempted. Global mesh sensitivity studies were prohibitive, so comparison of results from first and second order special discretization schemes was used to provide guidance for localized studies. Time step sensitivity was also studied.

A specific validation exercise of Fluent is provided using experimental data for a Ventilated Storage Cask (VSC) 17 system [16]. Advice is provided for nodalization and results given from a limited study on impact of turbulence model selection. A standard $\mathrm{k}-\varepsilon$ turbulence model is inadequate because Reynolds numbers in the air annulus are in transition from laminar to fully turbulent flow. Use of either a transitional SST-k- $\omega$ or a low Reynolds number $k-\varepsilon$ model produced temperature predictions that were fairly close to thermocouple readings.

The section of specific examples closes with a description of an exercise to aid in hydrogen management for a VVER containment [17]. Useful results can be obtained from single phase CFD models of the gas mixture as long as special models track removal of steam and hydrogen from the system. Before application to VVER this modeling approach was validated against the HYJET [18] and SETH [19] tests and results from HYMI [20] and ISP 47 [21] exercises. Lessons on nodalization and model selection learned from validation were carried into the final containment analyses.

\section{VERIFICATION, VALIDATION, AND DOCUMENTATION}

Computer simulation is much more than generating input and observing results. In an NRS project producing trusted results, these activities do not even occupy the majority of the staff time expended. A project must begin with a clear written statement of the problem, including identification of the specific system and scenario to be analysed.This statement is then reviewed by a panel of experts in the PIRT process, to identify parameters of interest and to rank physical phenomena (and by inference regions of the system) that most strongly influence these parameters. This identification of important phenomena guides the analyst in selection of an appropriate CFD code and in selecting optional physical models within that code. With knowledge of the system and significant physical phenomena, the panel is also responsible for identification of existing information that can be used to validate models over the range of conditions in the specified scenario.

The initial identification of significant physical phenomena, and associated validation is also an initial guide for spatial (and, if appropriate, temporal) discretization. If a specific validation problem has already been performed with the selected code, it should be reviewed for appropriate nodalization. If new validation calculations are required, a verification process is necessary to estimate errors associated with discretization before any comparison with data. This may result in an iterative adjustment of discretization until quantitative assurance is available that error associated with selection of the spatial mesh (and, where appropriate, time step) does not contaminate conclusions of the validation exercise. Errors in selection of mesh and time step size can result in incorrect choices for specific physical process models.

As part of the verification process we strongly recommend application of error analysis based upon Richardson extrapolation [see discussion in references 7 , 8, and 9]. Frequently, available time and computer resources restrict the rigor in estimation of discretization error. However, analysts must not use these restrictions as an excuse to abandon quantitative error estimates. Useful Richardson based error estimates can be obtained from 
comparison with results from one or two meshes that are coarser than the one used for final results, and error analysis using subsections of the mesh can also be very productive.

As part of verification, analysts must always be aware of their ability to introduce errors into input models, and developers' ability to leave errors in a code that can be very difficult to detect. It is extremely important to have some quality assurance (QA) procedure in place for any CFD project, part of which is a review of existing code verification relevant to all models being exercised. Although we do not recommend rigorous adherence to international standards for a QA program, we do recommend development of a program specifying requirements for the four primary components of QA: documentation of work; development procedures for input models and code; testing; and review of all work. Documentation is the least appreciated and perhaps most important of these. Writing a clear description of and justification for all aspects of an input model is an excellent way to catch errors, and is a necessary prerequisite for a good review process. The BPG contains extended discussion of all these QA components.

\section{CONCLUSIONS}

The need for Best Practice Guidelines and their systematic use by analysts became very clear during the assembly of the BPG. With the exception of individuals working within the ECORA project, most CFD practitioners in the nuclear safety community worked from personal experience, advice from co-workers, and at times code manuals. For those with experience in development and use of classic thermalhydraulic safety codes this process should come as no surprise. Even if the BPG document is not used on a regular basis for CFD projects, it should have significant value as a repository of expertise for training inexperienced CFD users.

As reflected in BPG, computer simulation is much more than generating input and observing results. The initial PIRT process guides the analyst in selection of an appropriate CFD code, optional physical models within that code, and validation tests appropriate for the final analysis. A well-designed QA process is necessary to minimize unintended errors in the input model, and verification through use of Richardson extrapolation is needed to bring discretization errors within acceptable bounds.

When the original 2007 BPG [1] was proposed, we realized that it could only be a starting point. We envisioned expansion of the document as more experience was gained from GAMA benchmark activity and from increased activity within the NRS community. We also believed that additional BPG documents should be written for specific applications such as containment analysis, thermal fatigue in piping, or pressurized thermal shock. These application specific documents would contain more detailed recommendations on appropriate selection of discretization and physical models and appropriate experimental data for validation. They could be created as part of new international standard problems sponsored by the NEA.

The CSNI has decided to manage evolution of the BPG document through the creation of a Wiki at the NEA web site. At the moment the original document has been converted to MediaWiki format and is open for review by a limited number of individuals associated with CSNI programs. A project is in progress at CEA and EDF to improve the guidelines for turbulence modeling. Another project is planned to include lessons learned from a NEA CFD benchmark on thermal mixing at a tee junction. We expect that the BPG Wiki will be publicly available as a link from http://www.nea.fr/nsd/csni/cfd/ by January 2011. The 2007 version of the BPG is currently available from a link on this web page.

\section{Acknowledgments}

Authors of the NEA/CSNI BPG document are listed below, along with the organizations providing support for their time and travel.

- Dr. Bub Dong Chung, Korea Atomic Energy Institute, Korea

- Mr. Franck Dubois, Institut de Radioprotection et de Sûreté Nucléaire (IRSN), France

- Dr. Frédéric Ducros, Commissariat à l'Energie Atomique (CEA), France

- Ms. Estelle Graffard, , Institut de Radioprotection et de Sûreté Nucléaire (IRSN), France

- Dr. Mattias Heitsch, Gesellschaft für Anlagen- und Reaktorsicherheit (GRS), Germany

- Mr. Mats E. Henriksson, Vattenfall Utveckling AB, Sweden

- Mr. Ed Komen, Nuclear Research and consultancy Group (NRG), Netherlands

- Dr. John H. Mahaffy, U.S. Nuclear Regulatory Commission, Penn State University

- Mr. Fabio Moretti, University of Pisa, Italy

- Dr. Tadashi Morii, Japan Nuclear Energy Safety Organization (JNES), Japan

- Dr. Petr Mühlbauer, Nuclear Research Institute (NRI), Czech Republic

- Dr. Ulrich Rohde, Forschungszentrum DresdanRossendorf (FZD), Germany

- Ms. Martina Scheuerer, Gesellschaft für Anlagen- und Reaktorsicherheit (GRS), Germany

- Dr. Brian L. Smith, Paul Scherrer Institut (PSI), Switzerland

- Dr. Chul-Hwa Song, Korea Atomic Energy Institute, Korea

- Dr. Tadashi Watanabe, Japan Atomic Energy Research Institute (JAERI), Japan

- Dr. Ghani Zigh, U.S. Nuclear Regulatory Commission (USNRC), United States

\section{REFERENCES}

[ 1 ] J. H. Mahaffy, B. Chung, F.Dubois, F. Ducros, E. Graffard, 
M. Heitsch, M. Henriksson, E. Komen, F. Moretti, T. Morii, P. Mühlbauer, U. Rohde, M. Scheuerer, B. L. Smith, C. Song, T. Watanabe, G. Zigh, "Best Practice Guidelines for the use of CFD in Nuclear Reactor Safety", Nuclear Energy Agency Report NEA/CSNI/R(2007)5 (2007).

[2] F. Menter, "CFD Best Practice Guidelines for CFD Code Validation for Reactor-Safety Applications," European Commission, 5th EURATOM Framework Programme, Report, EVOL-ECORA-D1 (2002).

[3] M. Casey and T. Wintergerste (ed.), "Special Interest Group on 'Quality and Trust in Industrial CFD' Best Practice Guidelines, Version 1,” ERCOFTAC Report (2000).

[4] M. Casey and T. Wintergerste, "The best practice guidelines for CFD - A European initiative on quality and trust," American Society of Mechanical Engineers, Pressure Vessels and Piping Division (Publication) PVP, v 448, n 1, p 1-10 (2002).

[5] WS Atkins Consultants, "Best Practices Guidelines for Marine Applications of CFD," MARNET-CFD Report (2002).

[6] AIAA, "AIAA Guide for the Verification and Validation of Computational Fluid Dynamics Simulations," AIAA Report G-077-1998.

[ 7 ] P. J. Roache, "Verification and Validation in Computational Science and Engineering," Hermosa Publishers, Albuquerque (1998).

[8] W. L. Oberkampf and T. G. Trucano, "Verification and Validation in Computational Fluid Dynamics, Progress in Aerospace Sciences, Vol. 38, pp. 209-272 (2002).

[9] W. L. Oberkampf, T. G. Trucano, C. Hirsch, "Verification, Validation and Predictive Capability in Computational Engineering and Physics," Applied Mechanics Reviews, Vol. 57, pp. 345-384 (2004).

[10] D. C. Wilcox, "Turbulence Modeling for CFD," Third Edition, DCW Industries, La Cañada, California (2006).

[11] G. E. Wilson, and B. E. Boyack, "The role of the PIRT process in experiments, code development and code applications associated with reactor safety analysis," Nuclear Engineering and Design, Vol. 186, pp. 23-37 (1998).

[12] Hirt, C. W., "Heuristic stability theory for finite-difference, J. Comp. Phys., Vol 2. No. 2, pp. 339-355 (1967).

[13] H.-M. Prasser, G. Grunwald, T. Höhne, S. Kliem, U. Rohde,
F.-P. Weiss, "Coolant mixing in a Pressurized Water Reactor: Deboration Transients, Steam-Line Breaks, and Emergency Core Cooling Injection," Nuclear Technology 143 (1), pp. 37-56 (2003).

[14] P. Weiss, H. Watzinger, and R. Hertlein, "UPTF experiment: a synopsis of full scale test results," Nuclear Engineering and Design, v 122, pp. 219-234 (1990).

[15] S. M. Willemsen and L. à Nijeholt, "Assessment of CFD modeling for PTS thermal-hydraulics using multiple scale experimental facilities," Proceedings of the 2006 International Congress on Advances in Nuclear Power Plants, ICAPP'06, pp. 1636-1645 (2006).

[16] M. A. McKinnon, R. E. Dodge, R. C. Schmitt, L. Eslinger, L. E. and Dineen, G.,. "Performance Testing and Analyses of the VSC-17 Ventilated Concrete Cask," Electric Power Research Institute Report TR-100305, Palo Alto, California (1992).

[17] R. Huhtanen (Editor), "Hydrogen management for the VVER $-440 / 213$ containment," Phare project service contract No HU2002/000-632-04-01, Final Report (2005).

[18] M. Heitsch, Wilkening, H., Baraldi, D., "CFD Modelling of Gas-Transport and Mixing Phenomena in the Battelle Experimental Facility for Nuclear Safety Applications", 7th World Congress of Chemical Engineering, Glasgow (2005).

[19] M. Andreani, K. Haller, M. Heitsch, B. Hemström, I. Karppinen, J. Macek, J.Schmid, H. Paillere, I. Toth, "A Benchmark Exercise on the use of CFD Codes for Containment Issues using Best Practice Guidelines: a Computational Challenge", OECD NEA Workshop CFD4NRS, Garching (2006).

[20] M. Carcassi, M. Jordan, M. Heitsch, F. Martin Fuertes, R. Monti, T. Kanzleiter, "Improved Modelling of Turbulent Hydrogen Combustion and Catalytical Recombination for Hydrogen Mitigation (HYMI)", 4th Framework Programme of the EC, Final Summary Report, Pisa (1999).

[21] J. Vendel, J. Malet, A. Bentaib, H. J. Allelein, S. Schwarz, E. Studer, H. Paillère, K. Fischer, M. Houkema, "Conclusions of the ISP-47 containment thermal-hydraulics," Proceedings of the $12^{\text {th }}$ International Topical Meeting on Nuclear Reactor Thermal Hydraulics, NURETH-12 (2007). 